Ethiopian Journal of Environmental Studies \& Management 8(4): 442 - 450, 2015.

ISSN:1998-0507

doi: http://dx.doi.org/10.4314/ejesm.v8i4.9

Submitted: February 28, 2015

Accepted: May 04, 2015

\title{
INVERSE RELATIONSHIP BETWEEN THE VOLUME OF INTRA-CITY TRAVEL PATTERN AND THE USE OF GLOBAL SYSTEM MOBILE COMMMUNICATION (GSM) IN LAGOS, NIGERIA
}

OSOBA, S.B.

School of Management Sciences, National Open University of Nigeria

Email: monitunde@yahoo.com

\begin{abstract}
Telecommunication is the growing enabler of activities at a distance. Its highest value is in helping us allocate our limited time and attention with the associated requirement of movement between various locations. Telecommunication facilitates a better level of proximity to the people and places we care about. However, this only happens when we consciously focus our use of telecommunication facility like GSM on deciding where and with whom we should be physically close. In spite of the widespread use of the Global System for Mobile Communication (GSM), its influence on various aspects of the society is yet to be empirically investigated. In particular, the inverse relationship between the volume of intracity trip patterns and the use of Global System for Mobile Communication of the Lagos residents. Data were collected from primary and secondary sources. A survey design was adopted. The study sample consisted of 2,500 households in Lagos metropolis. The questionnaire was administered in direct proportion to the population size of each of Local Government Areas (LGAS). Systematic sampling technique was used to select every tenth building on the identified streets. In a multi-family dwelling, random sampling was used to select one household. The household head or his/her representative was interviewed on intra-city trip patterns of GSM-owners of the household. The data collected were analyzed using simple linear regression and Analysis of Variance (ANOVA) .The usage of GSM generated almost two ( $6=1.72)$ trips per call and there was a significant relationship between the volume of trips and GSM usage $\left(F_{13}^{1}=5.72, p \leq 0.05\right)$. It is therefore recommended that transport planners in Lagos need to develop alternative intra-city transport systems. This can be achieved through a shift to the development of other land transport systems by policy makers.
\end{abstract}

Key Words: Travel patterns, Global System for Mobile Communication, Intra-city trips, Policy makers, Lagos.

\section{Introduction}

Urban travel takes place when inhabitants of urban centres carry out their different activities in different places whether by necessity or by choice. Studies (Ayeni, 1974; Adeniji, 1981; 1998; Ojo,
1990) have shown that in general, people tend to travel in order to obtain access to a variety of other people, services and facilities that are not available at the origins of their journeys. To what extent, how far and by what means they travel is a result of 
a complex interaction of socio-economic, political and physical factors (Adeniji, 1991). The nature and degree of influence of these factors however vary from city to city and even within a given urban centre. (Hausa and Schwab, 1987, Gordon et al., 1988, Rimmer, 1986 White 1990; Garling et.al, 1994, Bhat and Koppelman, 1999).

There exists a strong relationship between movement pattern and the locational distribution of activities over geographic space (Goddard, 1970). However, what is unclear is the relationship between telephone interaction pattern and the location of activities within the urban or sub-urban centres. Fundamental to this relationship is the role and impact of telecommuting technologies such as the telephone (Cherry, 1970 and Clark, 1973). This relationship, however, is determined by certain underlying variables, which are neither similar nor transferable from the developed areas of the world to the developing areas, particularly, the African countries (Adeniji-Soji, 1996, 2000). Abler (1968), Clark (1973) and Elliot-Hurst (1974) recognised the geographical and socio-economic importance of communication flow and its role as agent of change within the spatial system.

Telecommunication is the growing enabler of activities at a distance. Its highest value is in helping us allocate our limited time and attention with the associated requirement of movement between various locations. Telecommunication facilitates a better level of proximity to the people and places we care about. However, this only happens when we consciously focus our use of telecommunication facility like GSM on deciding where and with whom we should be physically close. An important feature of intra-city travel pattern in developing countries like Nigeria today is the increasing demand for travel as the regional economy of the country continues to grow with increasing emphasis on industrialization and trade. This phenomenon has necessitated increasing interaction among the people particularly those living in the urban centres. Reviewing the possible relationship between communication and travels, Salomon (1986), Nijkamp and Salomon (2001) independently contend that the relationship is not unidirectional as there are evidences, though few, to support this relationship. There are still arguments for and against the effects of communication and travels in general, even in the developed countries.

Short-term or daily movement consists of trips involving such activities as work, shopping and recreation, whereas longterm, or more permanent movement involves changing residence. With recent advancement in telecommuting technologies, movement patterns of urban residents might have changed considerably.

With the Federal Government of Nigeria in March 2001 granting licenses to three GSM operators in the country, it is believed that telecommunication and transportation would improve considerably. Lagos, the commercial capital of Nigeria, stands to benefit from this development and to ease the city of ever growing transportation complexities and problems. It is believed that this new technology would help to shape the movement pattern of people in the city thereby easing traffic congestion and delay in transit. All too often, telecommunications facilities are treated as an alternative to transportation systems and as a substitute for the physical movement of people and service. The growing use of telecommunications facilities like global system for Mobile Communication (GSM) is doing far more than influence where people work and live. It is likely to change the character of 
activities that occur in the home, workplace, social activities and business activities.

Lagos metropolis is being considered as a study area because it has an increasing demand of intra-city travel pattern. This has contributed to the highest rate of traffic congestion in Nigeria and the expectation is that the use of GSM will reduce this congestion by affecting the travel behaviour of people. Also, it is the commercial capital of Nigeria and it stands to benefit from the development of telecommunication especially GSM which can ease the ever-growing transportation complexities and problems.

\section{Methodology}

Both primary and secondary data were used for this research work. The first data set, which is the primary data was collected through the use of structured questionnaires administered on the urban metropolitan residents in order to determine their socio economic characteristics, such as income, occupational status, age, marital status, household size, travel pattern, level of ownership and accessibility to use of GSM facilities. The second data set, the secondary data, was gathered from relevant literature, journal articles and companies dealing with the Global system for Mobile communication in order to get necessary information on the number of GSM subscribers in the Lagos metropolis, year of establishment, network determining factors, and implementation procedure.

The estimated number of households which was 3,232,084, was taken for the population size, in order to determine the sample size, since there is no fast and hard rule guiding the choice of sample size. Bruton (1975) and Neuman (1994) recommended sample sizes between $10 \%$ and $1 \%$ for population areas of under 50,000 and 1 million respectively. However, Olokesusi (1994), Solanke
(2004) and Havlicek, (1985) utilised a sample size of less than $1 \%$ in their studies. In light of these, sample size of $0.08 \%$ of questionnaires was administered while 2,500 questionnaires were returned. In order to determine the number of households to be sampled in each of the Local Government Areas (LGAs) that constituted Lagos Metropolis, the calculated percentage $(0.08 \%)$ was multiplied with the estimated number of households in each Local Government Area (LGAs).

One type of sampling method was considered appropriate in the study. This is the Simple Random method. In each of the neighborhoods surveyed, random sampling was used to select the number of identified streets and it was also used to distribute the questionnaire among the households in each of the neighborhoods surveyed. In case of multi-family unit, one household was interviewed while random sampling was used to select samples of number of household buildings in which target respondents reside.

The questionnaire was structured into two parts, sections A and B. The first part considered the socio-economic characteristics of the respondents and their accessibility to GSM technologies.

The second part of the questionnaire dealt with the travel and activity pattern of urban residents. The information requested covered the details characteristics of the household trips for different purposes and for different days of the week. The basic question here included the mode-choice, purpose of trip, time spent on the journey and trip length. All the possible trips were divided into five purposes namely, work, shopping, recreation, social, and business trips. In collecting this information on travel activities, the questionnaire was given to urban residents for a week (Monday-Sunday). Thus, the questionnaire 
served as a self-administered travel diary and it was later collected after the seven days of a week.

Urban residents were requested to construct their urban trips within the one week. The choice of a full week was to be able to cover the totality of trips made by people both on weekdays and weekends. The reason for giving them the questionnaire to fill and record their trips activities for a week was to collect information from people while it was still fresh in their memory, thus enhancing the accuracy of the information.

The nature and strength of the relationship between Global system for Mobile Communication (GSM) and Volume of intra-city travel was established through simple linear regression analysis while Analysis of Variance (ANOVA) was used to test the significance of the results obtained from the analysis.

\section{Theoretical and Conceptual Underpinnings \\ Trip Generation Models}

Of equal relevance to this study are the trip generation models. They are essentially analytical techniques used in household trip generation in the literature and they include the growth factor, crossclassification or category analysis and multiple linear regression (Stopher and Meyburg (1975); Ortuzar and Willumsen (1990); and Oyesiku, (1995).

\section{Growth Factor Model}

The growth factor model attempts to estimate future number of trips by households for a specific purpose by any of specific categories of household attributes based on current trip rates. Formally the model is of the form in equation 1 .

$\mathrm{T}_{\mathrm{i}}=\mathrm{F}_{\mathrm{i}} \mathrm{t}_{\mathrm{i}} \ldots \ldots \ldots \ldots \ldots \ldots \ldots \ldots \ldots \ldots \ldots \ldots$

When $\mathrm{Ti}=$ future trips in Zone

$t_{i}=$ the current trips in the same zone

$F_{i=}$ the growth factor
The growth factor (fi) is defined as in equation 2 .

$F_{i}=f\left(P_{i}^{d}{ }^{d}{ }_{i} \mathrm{Ci}^{d}\right) / f\left(P^{i}{ }_{i} / i^{c} C^{c}\right) \ldots \ldots . .2$

Where ' $\mathrm{f}$ ' =direct multiplicative functions; P.I.C = variables such as population, income and car ownership respectively.

$\mathrm{d}, \mathrm{c}=$ the future and current situations respectively.

The growth factor assumes that the average trip rates will remain constant. Based on this estimate, future number of trips can be projected. Because of the assumption of constant trip rates, the model has been described as crude and tending to over estimate total number of trips (Bruton, 1995; Ortuzar and Willumsen, 1990) and therefore better suited for estimating trip ends for 'external/internal' and through movements (Oyesiku, 1995).

\section{Cross Classification or Category Analysis}

Cross-classification or category analysis is a similar model to the growth factor because it also attempts to estimate the number of trip productions on household basis for a given trip purpose as a function of household attributes. Furthermore, the model assumes that trip generation rates are relatively stable over time for certain household categories. The model in its standard form is in the form of equation 3 .

$\mathrm{t}^{\mathrm{p}}(\mathrm{h})=\mathrm{T}^{\mathrm{p}}(\mathrm{h}) / \mathrm{H}(\mathrm{h}) \ldots \ldots \ldots \ldots \ldots . .3$

where:

$\mathrm{t}^{\mathrm{p}}(\mathrm{h})=$ the total average number of trips with purpose $\mathrm{P}$ by households of type $\mathrm{h}$ at a time period $t$;

$\mathrm{Tp}(\mathrm{h})=$ the observed trips by members of households of type $h$ for

a purpose $\mathrm{p}$;

$H(h)=$ the number of household in types $h$

Like the Growth factor model, the cross classification model in its rudimentary form has some drawbacks. The most important of these is that it has no statistical goodness-of-fit measures and requires 
extremely large samples of households (Wooton and Pick, 1967; Douglas and Lewis, 1971).

\section{Multiple Regression Model}

Multiple Regression Model is among the commonly used tools in research for the understanding of functional relationships among multi-dimensional variables (King, 1969; Ayeni, 1979; Ademiluyi, 1996; Hanson, 1995; Oyesiku, 1990, 1995, 1996). The multiple regression model makes use of multiple regression analytical techniques to account for the influence of many variables on rate of trip generation in an area at a particular period. It is indeed the most wide spread method of trip generation study in the literature. Regression is a mathematically based procedure which has been programmed for most high-speed electronic computers. The techniques are therefore readily available to the analysts. In regression model, trip generation rate is treated as a dependent variable which is a function of one or more independent variables.

In mathematical form, the multiple regression model is of the form as presented in equation 4 .

$Y=a+b_{1} X_{1}+b_{2} X_{2}+b_{3} X_{3}+\ldots b_{n} X_{n}+e \ldots . .4$

Where:

$\mathrm{Y}=$ dependent variable

$\mathrm{a}=$ slope/intercept

$b_{1}, b_{2}, b_{n}=$ regression coefficients

$\mathrm{X}_{1}, \mathrm{X}_{2}, \mathrm{X}_{\mathrm{n}}=$ independent variables

$\mathrm{e}=$ error term or residuals.

The approach of this model is entirely mathematical. Therefore statistical test of reliability of the derived relationship can be applied with ease.

Generally, the use of regression models is based on some assumptions which include normality, linearity, independent variables to be measure error free, no autocorrelation, and that the samples are randomly selected from the sample frame
(Gould, 1970; Lewis-Beck, 1980; Ayeni, 1994). Violation of some of these assumptions may result in the equation containing co-efficient with theoretically incorrect signs, thus limiting the use of such equations in explaining the structure of the pattern under study.

The Regression model performs two basic functions: explanatory and predictive (Blalock, 1963; Hauser, 1974; Oyesiku, 1995).

The explanatory function of the model is concerned with an attempt to explain the separate influence of the independent variables in order to establish the importance of each or some combination of some of them on the dependent variables. The predictive function of the model is concerned with the aggregate or combined influence of all the independent variables on the dependent variable.

An important advantage of the multiple regression model over and above others in trip generation modelling is its capacity to allow for dummy variables to be included in the model. A number of household variables as trip generation determinants could not be measured or calibrated at interval, ratio or continuous scales, but in binary or dichotomous forms. The inclusion of the dummy or binary variables in the regression model is a process that increases the application of the model and does not cause its estimates to lose any of their properties (Lewis-Beck, 1980).

Although, using the derived equation form multiple regression analysis for prediction purpose has to be based on assumption that the regression co-efficient obtained at a given time will be relevant in the future. The technique has been widely accepted as a reliable tool in trip generation studies (Lewis-Beck, 1980; Oyesiku, 1990; Hanson 1995).

In this study, the multiple regression techniques are used to model the urban 
trips generation in Lagos metropolis. Two main reasons accounted for the choice of this model (multiple regression) among other trip generation models (growth factor and cross classification or category analysis). The first is its wider applicability, the ease of inclusion of dummy variables as determinants of household trip demand, and the disaggregated nature of the data in trip generation as utilized by Ayeni (1979) Lewis-Beck (1980) and Oyesiku (1990). Secondly, there is its explanatory function identifying the separate influence of the socio-economic and demographic variables of the households in order to establish the importance of the relationship between each of these variables and volume of trip generated (Wootton and Pick, 1967; Wilson, 1974; Stopher and McDonald, 1983, Ogunjumo, 1986).

\section{Result and Discussion}

Attempt is therefore made in this study to examine the Inverse relationship between Volume of Intra-City Travel Pattern and use of Global System for Mobile Communication. In order to achieve the number of trips made by GSM owners is considered as the dependent variable while the usage of GSM phone for calls is considered as the independent variable in a regression analysis.

Model of the Relationship between IntraCity Travel and the GSM Phone Call

The simple correlation analysis was used to examine the relationship between the number of the trips made by GSM phone users and the number of GSM phone calls made by them, given as equation:

$$
\mathrm{Y}=\mathrm{bx}+\mathrm{e}
$$

Where $\mathrm{Y}=$ dependent variable or number of trips of GSM owners

$\mathrm{X}=$ independent variable or number of GSM phone calls of GSM owners.

$\mathrm{e}=$ an error term or disturbance term.

Table 4.1: Model Summary of the relationship between volume of trips and GSM usage

\begin{tabular}{lccccccc}
\hline & $\begin{array}{c}\text { Sum of } \\
\text { squares }\end{array}$ & $\begin{array}{l}\text { Degree of } \\
\text { freedom }(\mathrm{df})\end{array}$ & Mean square & F-value & P-value & $\mathrm{R}$ & R.square \\
\hline Regression & 792103.3 & 1 & 792103.28 & 5.72 & 0.041 & 0.72 & 0.5 \\
Residual & 14328556 & 13 & 1102196.65 & & & & \\
Total & 15120660 & 14 & & & & & \\
\hline
\end{tabular}

The relationship between the volume of trips and GSM usage is computed as 5.72. The percentage explanation of volume of trips provided by GSM usage is given as $50 \%$ that is R square value. To test for the significance of the relationship, the Analysis of Variance (ANOVA) is carried out and the result is presented in table 4.1. The computed F-value of 5.72 is significant at 5\% level of significance as the observed P-value of 0.041 is lower than 0.05 or $5 \%$. Hence, we accept that there is a significant relationship between volume of trips and GSM usage in Lagos metropolis. That is, the more the information through the usage of GSM, the more the desire to travel. The details of the regression equation as computed to determine the level of the relationship between the volume of trips and the GSM usage are presented in table 4.2 below. 
Table 4.2 Regression Results of the relationship between volume of trips and GSM usage

\begin{tabular}{lcccc}
\hline & $\begin{array}{l}\text { Regression } \\
\text { coefficient (B) }\end{array}$ & $\begin{array}{l}\text { Standard coefficient } \\
\text { (beta) }\end{array}$ & T-value & $\begin{array}{l}\text { Observed } \\
\text { significance value }\end{array}$ \\
\hline $\begin{array}{l}\text { Constant } \\
\text { GSM usage (independent } \\
\text { variable) }\end{array}$ & 2198.53 & 0.23 & 3.020 & 0.010 \\
\hline
\end{tabular}

The equation expressing the relationship between the volume of trips and GSM usage as derived from table 4.2 is given as: Volume of trips $=2198.53+1.72(\mathrm{GSM}$ usage)

The above equation specifies volume of trips as dependent variable, which is being predicted by GSM usage (the independent variable). It is observed from the regression equation that the usage of GSM generates almost two (1.72) trips per call. Hence, the hypothesis that "there is an inverse relationship between the volume of intra-city travel pattern and the use of Global System for Mobile Communication is rejected since relationship is positive and its calculated t-value of 2.848 is significant at $5 \%$ level of significance

\section{Conclusion}

This study contends that the more the information that is available through telecommunication particularly the GSM, the more the desire to travel. The study shows that they are not likely to be substituted for by Global System for mobile communication (GSM). The study reveals that business transactions, work, shopping, social and recreation activities involve face to face contact requiring physical movement between places. The GSM and other forms of telecommunications in general enable contacts to be made frequently between people located at different points. The frequent contacts, implying frequent interaction, in turn bring about more information not only about business, social, work, shopping, recreation but also other multifarious activities around that may require physical movement to attend. New or additional trips are made as a result on the frequent interactions. This finding is in line with the view of Owen (1987) that telecommunications might reduce unwanted intra-city trips, and offer new ways of doing business, and thus expected to increase opportunities and choices rather than affect any net reduction of total volume of trips. This implies that the effect of telecommunications may be to increase the total amount of travel for these activities.

In developing countries like Nigeria where the study took place, the trips made in respect of different activities like work, business, social, shopping and recreation may not be substituted for by GSM. The major reasons being that of low level of technology, nature of commercial transactions which required physical or face to face contacts and more importantly socio-cultural background that is still much in favour of physical contacts. . It is therefore recommended that transport planners in Lagos need to develop alternative intra-city transport systems. This can be achieved through a shift to the development of other land transport systems by policy makers.

\section{References}

Abler, R.F. (1968). The geography of Communication - Transportation Geography: comments and reading. New York: McGraw-hill Books Company.

Adeniji-Soji, J.O. (1996). Patterns of Telecommuting and Intra-city travel: A case study of Ibadan metropolis, Nigeria, Unpublished Ph.D Thesis, 
Department of Geography, University of Ibadan, Ibadan.

Adeniyi, K. (1985). "Urban Transportation System in Nigeria" ODU: A Journal of West African Studies, 28:81-97.

Adeniji, K. (1991). "Urban Mobility Crisis, where do we go from here?" Paper delivered at Ogun State Public Service Forum Gateway Hotel, Abeokuta.

Adeniji, S.A. (1981). "Public Transportation and Urban Development strategy in Nigeria" Unpublished Ph.D Thesis university of Wales, Pontain.

Adeniji, K. (2000). "Transport challenges in Nigeria in the next to a declares" Transport studies Unit NISER Ibadan.

Ayeni, M.A.O. (1974). "Predictive Modelling of Urban Spatial Structure: the example of Jos, Benue-Plateau State, Nigeria. Unpublished Ph.D. Thesis, University of Ibadan.

Ayeni, B (1979). Concepts and Techniques in Urban Analysis Croom Helm Ltd, London.

Bhat, C.B. and Koppelman, F.S. (1999). "A retrospective and prospective survey of time use research" Transportation 26: 119-139.

Bruton, M.J. (1995). Introduction to Transport Planning Hutchinson, London.

Cherry, C. (1970). Human Communication: Technology and Urban Planning in D. Jones (Ed), Communication and Energy in Changing Urban Environments, 117-130. Butterworths London.

Clark, D. (1973)."Communication and the Urban Future. A case study of Trunk Telephone call patterns in Wales" Regional Studies, vol. 7, No. 3, pp. 315-321.

Elliot-Hurst, M.E. (1974). Transportation Geography: Comments and Readings.
Garling, T. Kwan, and Golledge, R.G. (1994). "Computational Process Modelling of household activity scheduling" Transportation Research, 28B(5): 355-364.

Gordon, P., Kumaar, A and Ricahrdson, H.W. (1988). "Beyond The Journey to work" Transportation Research, A22: 419-426.

Gordon, P. and Richardson, H.W. (1997). "Are Compact Cities a Desirable Panning Goal? Journal of the American Planning Association (Winter) Vol. 63, No. 1.

Gottman, J. (1983). "Urban Settlements and Telecommunications" Ekistics.

Hausa, S. and Schwab, M. (1987). Accessibility and Intra urban travel, Environment and Planning, 735-748.

Ogunjumo, A. (1986). "The Pattern of Trip generating at Ile-Ife" in Journal of Nigerian Institute of town Planners, VI and VII, 99-144.

Ojo, O.E. (1990). Urban Travel-activity Pattern: A Case Study of Ibadan, Nigeria Unpublished Ph.D. Thesis, University of Ibadan.

Ortuzar, J.D. and Willumsen, L.G. (1999). Modelling Transport, john Wiley and Sons Ltd; chi Chester.

Owen, W. (1987). "Transportation and Society" In Transportations Planning Handbook: Institute of Transportation Engineers (Eds) year Edward Jnr.

Oyesiku, O.O. (1990). "Inter-Urban travels pattern in Nigeria". A Case Study of Ogun State, (Unpublished Ph.D Thesis University of Benin City, Nigeria).

Oyesiku, O.O. (1995). "An Analysis of Demand for Later-city trip Generation Attributes of a Developing State in Nigeria in Journal of transport Studies Vol. 11, 1 \& 2, Vol. 12, 1 \& 2, pp. 112-130. 
Oyesiku, O.O. (1996). Inter-City Travels and Telecommunications relationship: an Explorative Study in Nigeria" Journal of Ife Social Science pp. 3749, University of Ife Press.

Rimmer, P.J. (1986). Rikisha to rapid transit: Urban Public Transport
Systems and Policy in South East Asia Sydney: Pentagon.

White, P.R. (1990). "Inadequacies of Urban public transport systems" in Dimitriou, H.T. (ed), Transport Planning for Third World Cities London Routledge pp. 85-116. 